\title{
Strut-and-Tie Design Methodology for Three-Dimensional Reinforced Concrete Structures
}

\author{
Liang-Jenq Leu'; Chang-Wei Huang²; Chuin-Shan Chen, M.ASCE ${ }^{3}$; and Ying-Po Liao ${ }^{4}$
}

\begin{abstract}
A strut-and-tie design methodology is presented for three-dimensional reinforced concrete structures. The unknown strut-andtie model is realized through the machinery of a refined evolutionary structural optimization method. Stiffness of struts and ties is computed from an evolved topology of a finite element model to solve statically indeterminate strut-and-tie problems. In addition, compressive strength for struts and nodal zones is evaluated using Ottosen's four-parameter strength criterion. Numerical examples are studied to demonstrate that the proposed design methodology is suitable for developing and analyzing three-dimensional strut-and-tie models for reinforced concrete structures.
\end{abstract}

DOI: 10.1061/(ASCE)0733-9445(2006)132:6(929)

CE Database subject headings: Concrete, reinforced; Design; Finite elements; Optimization; Three-dimensional analysis; Struts; Trusses; Ties.

\section{Introduction}

In designing reinforced concrete structures, it is common practice to classify portions of structures as either B or D regions. Most design practices for B regions are well developed. On the other hand, design for D regions, such as deep beams, corbels, joints, and pile caps, is mostly based on heuristic methods and past experience (Hsu 1993; MacGregor 1997).

One approach to replace ad hoc D-region design practices is the strut-and-tie method (Schlaich et al. 1987). In this method, the complex flow of internal forces in $\mathrm{D}$ regions is transformed to a truss-like structure carrying the imposed loading to adjacent $\mathrm{B}$ regions or to its supports. A strut-and-tie model consists of struts, ties, and nodes. Struts are compression members which represent resultants of parallel or fan-shaped compressive stress fields. Ties are tension members which mostly represent reinforcing steels, but can occasionally represent prestressing tendons or tensile stress fields. Nodes are the locations where the axes of the struts, ties, and concentrated forces intersect. Nodal zones are thus subject to a multidirectional stress state. The strut-and-tie method offers numerous advantages (ASCE-ACI 1998) and has been adopted in design code provisions recently (FIP 1996; ACI 2002).

\footnotetext{
${ }^{1}$ Professor, Dept. of Civil Engineering, National Taiwan Univ., Taipei 10617, Taiwan (corresponding author). E-mail: 1jleu@ntu.edu.tw

${ }^{2}$ Assistant Professor, Dept. of Industrial Engineering and Management, St. John's Univ., Taipei 25135, Taiwan. E-mail: cwhuang@ mail.sju.edu.tw

${ }^{3}$ Associate Professor, Dept. of Civil Engineering, National Taiwan Univ., Taipei 10617, Taiwan. E-mail: dchen@ntu.edu.tw

${ }^{4}$ Research Associate, Dept. of Civil Engineering, National Taiwan Univ., Taipei 10617, Taiwan. E-mail: liao@caece.net

Note. Associate Editor: Elisa D. Sotelino. Discussion open until November 1, 2006. Separate discussions must be submitted for individual papers. To extend the closing date by one month, a written request must be filed with the ASCE Managing Editor. The manuscript for this paper was submitted for review and possible publication on September 5, 2003; approved on June 3, 2005. This paper is part of the Journal of Structural Engineering, Vol. 132, No. 6, June 1, 2006. (CASCE, ISSN 0733-9445/ 2006/6-929-938/\$25.00.
}

Although the strut-and-tie method is conceptually simple, its realization for complex $\mathrm{D}$ regions is not straightforward. The major complexity involves how to transform a continuous description of a structural region to a discrete strut-and-tie model (Liang et al. 2002). Additional complexities include how to account for stiffness of struts and ties and how to evaluate concrete effective strength (Yun 2000; Tjhin and Kuchma 2002). For the strut-and-tie method to be reliably adopted in design practice, it is imperative to manage these complexities in a unified and consistent manner.

The advances in the field of structural topology optimization open up new ways of resolving the implementation complexities of the strut-and-tie method (Liang et al. 2000, Liang et al. 2002; Ali and White 2001; Biondini et al. 2001). However, these studies are mainly focused on two-dimensional structures. Thus, the main objective of this study is to develop a strut-and-tie design methodology for three-dimensional reinforced concrete structures. In the following, the deficiencies of the conventional strut-and-tie design methodology are addressed, in particular for tackling three-dimensional problems. A design methodology aimed to resolve these deficiencies is then delineated. In the proposed methodology, an appropriate strut-and-tie model is generated from structural topology optimization. Member forces of a statically indeterminate strut-and-tie model are calculated based on the evolved topology. The bearing capacity of strut-and-tie models is predicted by a concrete failure criterion. Finally, two numerical examples are studied to demonstrate the applicability of this proposed design methodology.

\section{Challenges of Conventional Strut-and-Tie Design Methodology}

The standard procedure of the conventional strut-and-tie design methodology can be found in design code provisions (ACI 2002); a conceptual flowchart is depicted in Fig. 1 for later comparison in this study. Generally speaking, this procedure is a trial-anderror iterative design process based mainly on designers' intuition and experience. 


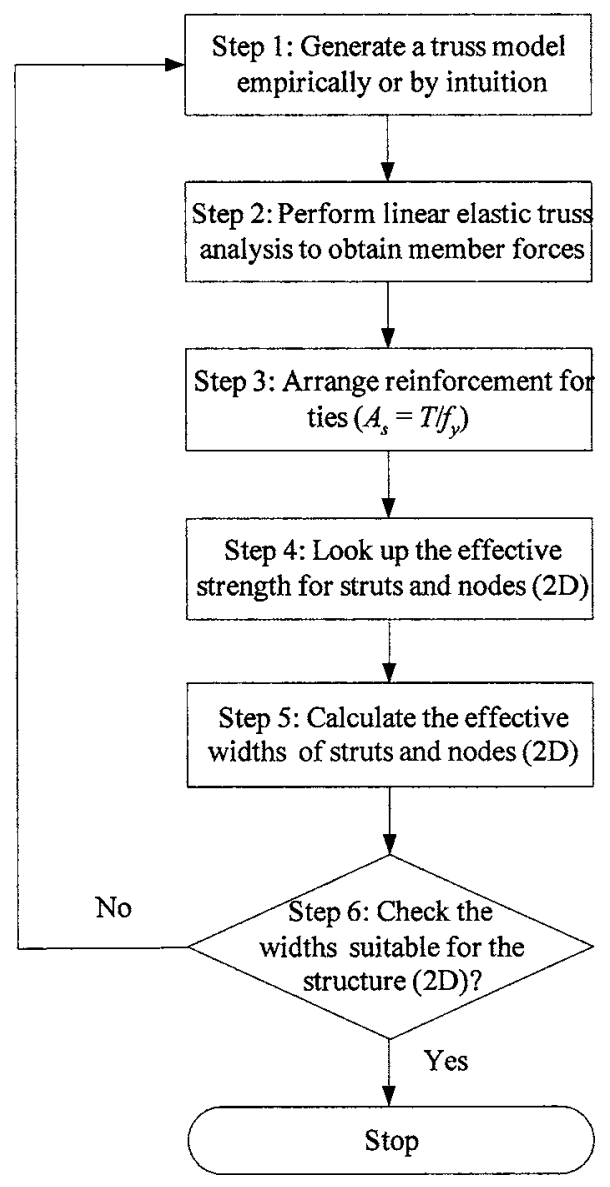

Fig. 1. Flowchart of conventional strut-and-tie design methodology

The conventional design methodology faces at least three major challenges in design practices. The first challenge is that it is not easy to generate an appropriate strut-and-tie model for a structure, especially a three-dimensional one. In the literature, most strut-and-tie models are developed by utilizing stress trajectories from finite element analysis (Schlaich et al. 1987; Schlaich and Schäfer 1991). Directions of struts and ties are taken in accordance with those directions of principal compressive and tensile stresses, respectively. This strategy, however, suffers from two drawbacks. First, for a region with complex stress distribution, it is not a simple task to generate a corresponding strut-andtie model by inspection. Second, for a three-dimensional region, it is very difficult for designers to visualize the stress trajectories in the interior. Recently, structural topology optimization methods have been employed to generate strut-and-tie models automatically for two-dimensional reinforced concrete structures. For example, Ali and White (2001) and Biondini (2001) used a linear programming method to find an optimum strut-and-tie model. A concrete structure was replaced by a ground structure consisting of many truss members. However, the discrete ground discretization may not be adequate to model the continuous structure. Consequently, the resulting strut-and-tie model may not faithfully represent the structure (Liang et al. 2000).

The second challenge faced by the conventional design methodology is the issue concerned with stiffness determination of each member in a statically indeterminate strut-and-tie model. One way to handle the statically indeterminate case is to employ the so-called plastic truss method. However, care must be taken because of strain compatibility requirements and limited ductility in concrete (Tjhin and Kuchma 2002). Schlaich and Schäfer (1991) suggested that a statically indeterminate strut-and-tie model could be decomposed into several statically determinate ones. Each statically determinate truss model was then responsible for sustaining an equal portion of external loading. However, it is not clear whether or not a statically indeterminate truss model can always be decomposed. In addition, the assumption that each statically determinate truss model takes the same external loading may not be reasonable (Ali 1997). Recently, Yun (2000) proposed an iterative approach to determine the relative stiffness of statically indeterminate strut-and-tie members. However, its convergence property may not be assured.

The third challenge faced by the conventional design methodology is related to the issue of indirectly evaluating concrete bearing capacity. The effective compressive strengths of the struts and nodes are first obtained by looking up codes and guidelines (e.g., Schlaich et al. 1987; FIP 1996; MacGregor 1997; ACI 2002). The effective width of the strut is then computed from dividing the member force by the effective strength. The shapes and dimensions of the nodes are determined after the widths of incoming struts are resolved. Finally, the truss model with finite widths is evaluated to determine its suitability for the structure. If the widths of struts are not suitable, the selected strut-and-tie model has to be modified. For two dimensions, values for effective compressive strengths of struts and nodal zones are specified in codes and guidelines. However, for three-dimensional strutand-tie models, no proven guidelines are yet available.

\section{Proposed Strut-and-Tie Design Methodology}

In this study, a strut-and-tie design methodology is proposed to overcome the above-mentioned difficulties. The development is centered upon the concept of transforming the design to a topology optimization problem of a continuum structure (Liang et al. 2002). In addition, the proposed methodology utilizes information passing from a continuum to determine effective stiffness and strength properties needed in a strut-and-tie model. Doing so thus allows us to reduce the ambiguous features encountered by the conventional method.

\section{Refined Evolutionary Structural Optimization Method}

To generate a three-dimensional strut-and-tie model for a structure, the concept of topology optimization is employed herein. Several methods have been proposed in the literature to solve the topology optimization problem. Among them, the evolutionary structural optimization (ESO) method (Xie and Steven 1993) is one of the most popular methods. The ESO method is widely reported and currently received intensive attention. One reason is that the method is conceptually simple but the obtained results are quite accurate compared with other methods. The other reason is that it is easy to implement the ESO method in conjunction with the finite element method.

Despite its popularity, the ESO method proposed by Xie and Steven suffered some weaknesses (Zhao et al. 1998). In this paper, the ESO is improved to find the optimal topology for a three-dimensional continuum, from which the strut-and-tie model can be derived. To distinguish the original ESO method from the refined ESO method, the latter is denoted as the refined ESO (RESO) method in this study. A brief introduction to the RESO method is presented herein; details can be found in Huang (2003). 


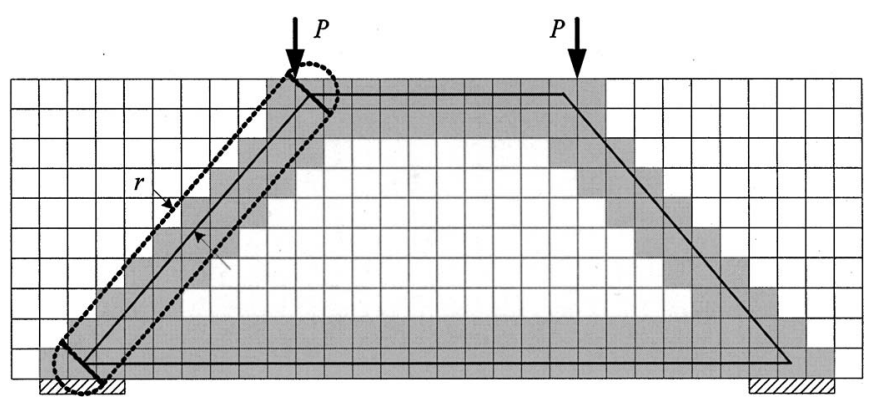

Fig. 2. Illustration of region (enclosed by dashed lines) for two-dimensional truss element with cutoff distance $r$

The RESO method starts from a design domain constructed by a finite element model with given loading and support conditions. Through gradually removing ineffective materials, one can obtain new topologies of the structure that are more effective than the initial one. The material efficiency is determined from the strain energy density of each element. Elements are deleted when their strain energy densities are less than a rejection ratio (RR) times the average strain energy density of the structure $\left(w_{\text {ave }}\right)$. The condition can be expressed as

$$
\text { if } \quad w_{i}<R R \times w_{\text {ave }} \text { then the } i \text { th element is deleted }
$$

where $w_{i}=$ strain energy density of the $i$ th element defined as

$$
w_{i}=\frac{1}{2 V_{i}}\left\{u_{i}\right\}^{T}\left[k_{i}\right]\left\{u_{i}\right\}
$$

in which $\left\{u_{i}\right\}=$ displacement vector; $\left[k_{i}\right]=$ element stiffness matrix; and $V_{i}=$ volume of the $i$ th element, respectively.

The finite element analysis and element elimination cycle are repeated using the same RR until a steady state is reached; this state represents null element deletion according to Eq. (1). At this state, an evolution rate (ER) is introduced and added to (RR)

$$
\mathrm{RR}=\mathrm{RR}+\mathrm{ER}
$$

in which ER is used as an increment of RR so that the elimination criterion of elements is increased to the next level. It is worth noting that the evolutionary process works properly only when the number of elements removed at each evolution is small (Hinton and Sienz 1995). If a large number of elements are removed in a typical design evolution, it may result in missing the optimum topology in the evolutionary process. To avoid this problem, a maximum percentage of elements that can be removed in each design evolution are prescribed. In this study, $1 \%$ of the elements in the initial design domain are allowed to be removed in each evolution. If the number of removed elements in each evolution exceeds this maximum number, the current RR will be reduced until the number of removed elements is smaller than the maximum threshold.

Table 1. Values for Ottosen's Four-Parameter Concrete Failure Criterion

\begin{tabular}{ccccc}
\hline$f_{t} / f_{c}^{\prime}$ & $a$ & $b$ & $k_{1}$ & $k_{2}$ \\
\hline 0.08 & 1.8076 & 4.0962 & 14.4863 & 0.9914 \\
0.10 & 1.2759 & 3.1962 & 11.7365 & 0.9801 \\
0.12 & 0.9218 & 2.5969 & 9.9110 & 0.9647 \\
\hline
\end{tabular}

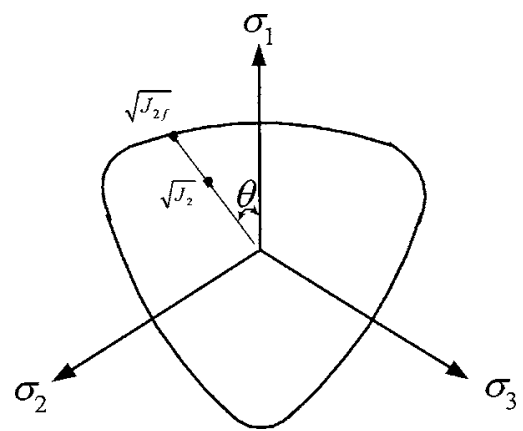

Fig. 3. Illustration of second deviatoric stress invariant of applied load and of material failure state

The evolutionary process continues until a defined stop criterion is reached. There are several ways to define the stop criterion in the literature (Xie and Steven 1993). In this study, the performance index (PI) proposed by Liang and Steven (2002) and Liang et al. (2002) is adopted to monitor whether the optimal topology is reached. The index provides a measure of efficiency for different design evolutions. A higher value of PI means a more efficient topology for the structure.

The performance index, in terms of the total strain energies and volumes at the initial and $i$ th design evolutions, can be defined as

$$
\mathrm{PI}=\frac{W^{0} V^{0}}{W^{i} V^{i}}
$$

where the superscripts 0 and $i$ represent the initial and $i$ th design evolutions, respectively. In addition, $W$ and $V$ denote the total strain energy and volume of the structure, respectively. The performance index increases from unity to a maximum value when the inefficient elements are removed gradually. However, further element removal from the "optimal" topology structure that has the highest value of the index will lead to decrease of the stiffness of the structure. It then results in decreasing values of the performance index.

Sometimes, it is found that elements with restraints may be removed without losing structural stability during the evolutionary process. However, removal of restraints leads to change of design boundary conditions in the strut-and-tie design method. Therefore, once any element with restraints is removed in a typical design evolution, the evolutionary process is also stopped.

The proposed RESO procedures can be summarized as follows.

1. Assign initial values: $\mathrm{RR}=1 \%$; $\mathrm{ER}=1 \%$;

2. Discretize the design domain with a finite element mesh;

3. Perform linear elastic analysis for given loads and boundary conditions;

4. Calculate strain energy density values of all elements and performance index of the structure;

5. Smooth element strain energy density values to avoid the checkerboard pattern ( $\mathrm{Li}$ et al. 2001) and calculate the average strain energy density;

6. Remove inefficient elements with lower strain energy density values according to Eq. (1) with the constraint that the number of removed elements in each evolution shall be less than $1 \%$ of the number of elements of the initial structure. Otherwise, a smaller value for RR shall be used; and

7. Repeat steps 3-6 until a stop criterion is reached. 


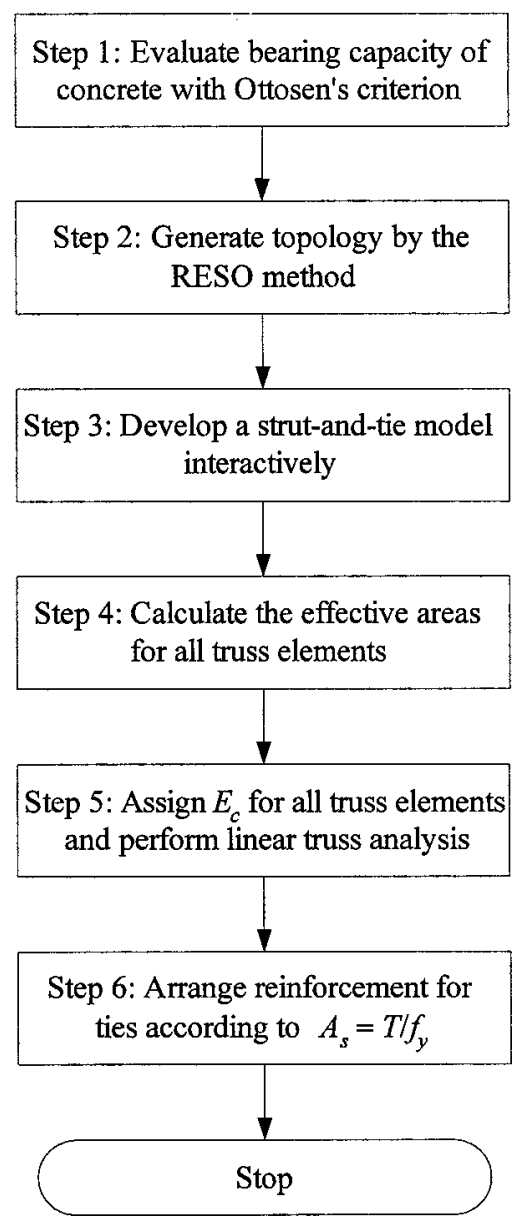

Fig. 4. Flowchart of proposed strut-and-tie design methodology

In summary, the main differences between the RESO and ESO methods are the removing algorithm in each evolutionary iteration, the smooth process to prevent checkerboard patterns, and the stop criterion by the performance index. Three remarks regarding the practical implementation of the RESO method are listed in order. First, removed elements are ignored in assembling the global stiffness matrix in the RESO method. This technique has the advantage in solving the equilibrium equations of finite element analysis because the number of degrees of freedom becomes less and less during the evolutionary process. Second, the removal
Table 2. Member Forces in Anchorage Block Design Example from FIB Model

\begin{tabular}{lccccc}
\hline Members & $\begin{array}{c}\text { Length } \\
(\mathrm{cm})\end{array}$ & $\begin{array}{c}\text { Member } \\
\text { force } \\
(\mathrm{kN})\end{array}$ & Members & $\begin{array}{c}\text { Length } \\
(\mathrm{cm})\end{array}$ & $\begin{array}{c}\text { Member } \\
\text { force } \\
(\mathrm{kN})\end{array}$ \\
\hline $\mathrm{T}_{1}$ & 40.0 & 580.7 & $\mathrm{C}_{1}$ & 78.5 & $-1,139.1$ \\
$\mathrm{~T}_{2}$ & 67.5 & $3,171.2$ & $\mathrm{C}_{2}$ & 98.8 & $-2,665.1$ \\
$\mathrm{~T}_{3}$ & 60.0 & 1,618 & $\mathrm{C}_{3}$ & 90.3 & $-3,761.2$ \\
$\mathrm{~T}_{4}$ & 67.5 & 2,800 & $\mathrm{C}_{4}$ & 72.1 & $-1,047.0$ \\
$\mathrm{~T}_{5}$ & 40.0 & 1,660 & $\mathrm{C}_{5}$ & 78.5 & $-3,256.1$ \\
$\mathrm{~T}_{6}$ & 67.5 & 2,800 & - & - & - \\
$\mathrm{T}_{7}$ & 40.0 & 1,660 & - & - & - \\
\hline
\end{tabular}

of elements may result in the case where one or more remained elements do not have sufficient connectivities with other elements. For instance, if a quadrilateral element is connected to the other elements by only one node, the structural stiffness matrix will become singular. In this case, this element shall be removed in order to have a nonsingular stiffness matrix. Finally, two stop criteria are adopted in the RESO method. The evolutionary process is stopped when the performance index has reached its maximum or elements with restraint are removed during the process.

\section{Statically Indeterminate Strut-And-Tie Model Analysis}

To compute relative stiffness of truss members, a simple stiffness finding algorithm is developed. It is necessary because after an appropriate strut-and-tie model is selected, member forces of the model need to be determined. For statically determinate strut-andtie models, member forces can be obtained from equilibrium equations. However, for statically indeterminate strut-and-tie models, equilibrium equations and relative stiffness of members are needed to compute member forces. The truss-like evolutionary topology offers a good estimate for the relative stiffness of truss members. Each truss member within its reach should comprise some number of remaining finite elements. These finite elements are naturally potential candidates to contribute stiffness for the truss member.

Our stiffness finding algorithm can thus be established as follows. First, a cutoff distance $r$ is chosen to allocate those finite elements within the reach of a truss member. Fig. 2 illustrates the region generated by the cutoff distance in two dimensions. In

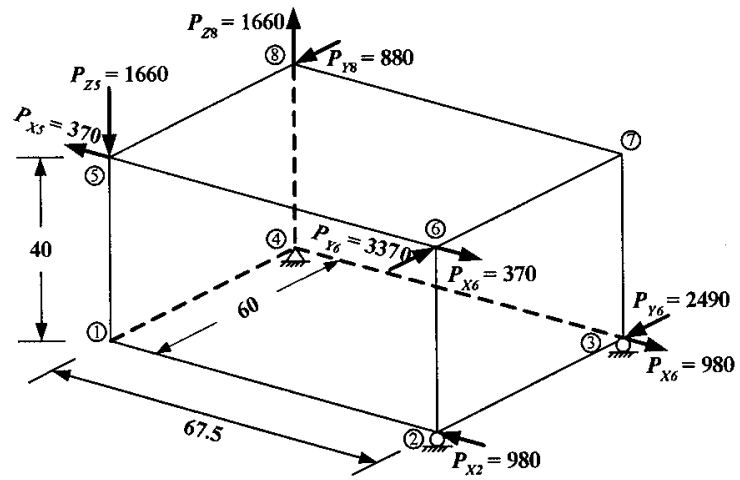

(a)

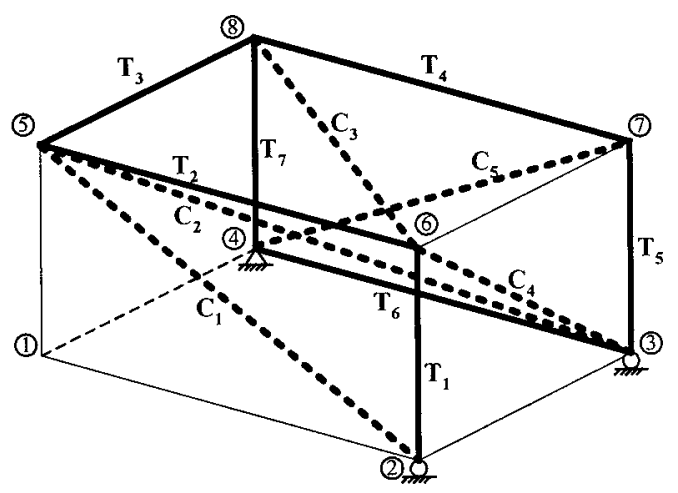

(b)

Fig. 5. Anchorage block design example of FIB (load unit: kN): (a) configuration; (b) strut-and-tie model 


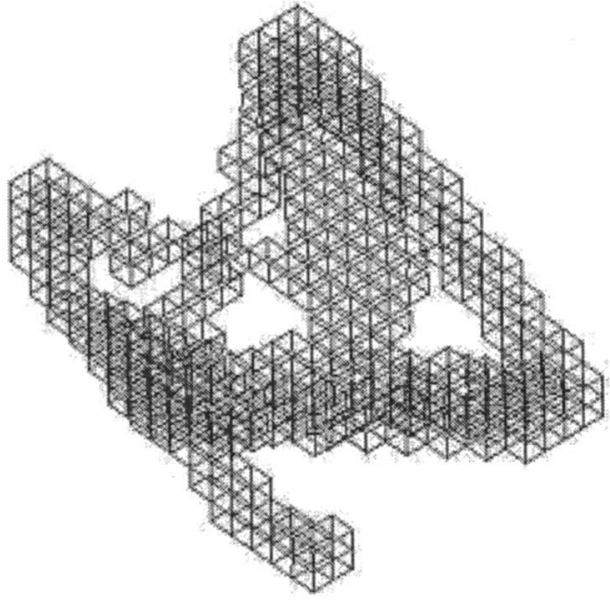

(a)

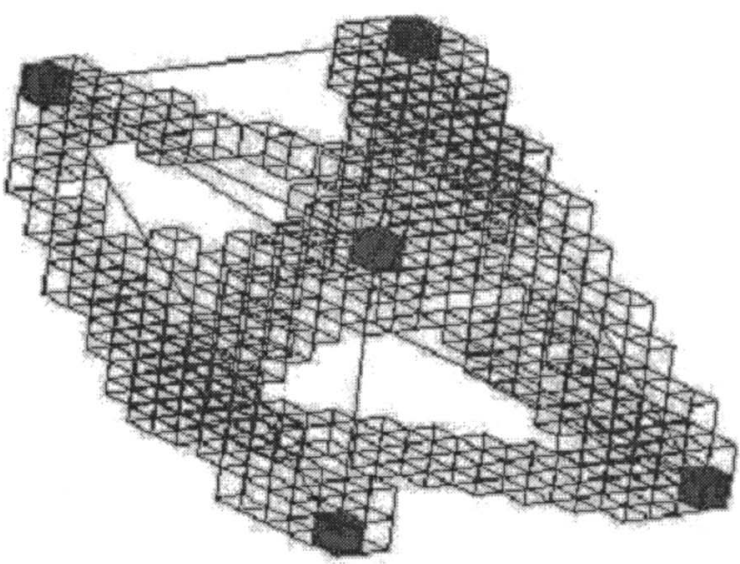

(b)

Fig. 6. Optimal topology of anchorage block: (a) evolutionary structural topology; (b) connecting truss elements

three dimensions, this cutoff distance yields a region with a cylinder around the longitudinal axis and two hemispheres around two nodes of this truss member. Second, remaining finite elements from the evolved topology located within this region are identified. The effective area for the truss member is then obtained from dividing the summing volume by the length of the truss member. The proposed procedure can be summarized as follows:

1. For the $i$ th truss member connecting with the $j$ th and $k$ th solid elements, calculate the length $L_{i}$ for the truss member

$$
L_{i}=\sqrt{\left(x_{j}-x_{k}\right)^{2}+\left(y_{j}-y_{k}\right)^{2}+\left(z_{j}-z_{k}\right)^{2}}
$$

2. For the $q$ th remaining element with the central point $\left(x_{q}, y_{q}, z_{q}\right)$, calculate the projected point $\left(x_{p}, y_{p}, z_{p}\right)$ on the longitudinal axis of the truss

$$
\begin{gathered}
\left\{\begin{array}{l}
x_{p}=x_{j}+\left(x_{k}-x_{j}\right) t \\
y_{p}=y_{j}+\left(y_{k}-y_{j}\right) t \\
z_{p}=z_{j}+\left(z_{k}-z_{j}\right) t
\end{array}\right. \\
t=\frac{\left(x_{q}-x_{j}\right)\left(x_{k}-x_{j}\right)+\left(y_{q}-y_{j}\right)\left(y_{k}-y_{j}\right)+\left(z_{q}-z_{j}\right)\left(z_{k}-z_{j}\right)}{\left(L_{i}\right)^{2}}
\end{gathered}
$$

3. Calculate the distance $d_{p q}$ of all remaining elements to the longitudinal axis of the $i$ th truss. The volume of the $i$ th truss member $V_{i}$ is then the sum of the volumes of the solid elements within the cutoff distance $r$

$$
\begin{gathered}
d_{p q}=\sqrt{\left(x_{q}-x_{p}\right)^{2}+\left(y_{q}-y_{p}\right)^{2}+\left(z_{q}-z_{p}\right)^{2}} \\
\text { if } d_{p q}<r: V_{i}=V_{i}+V_{\text {elem }}^{q}
\end{gathered}
$$

in which $V_{\text {elem }}^{q}=$ volume of the $q$ th finite element.

4. Finally, the effective area of the $i$ th truss member, $A_{i}$, can be obtained by dividing the volume with the member length $L_{i}$

$$
A_{i}=\frac{V_{i}}{L_{i}}
$$

We note that the evaluation of effective areas of truss members depends naturally on the choice of cutoff distances. However, thanks to the truss-like arrangement of the remaining finite elements, it is generally not very difficult to identify a suitable range of cutoff distances for a given problem. In this range, member forces of truss members are relatively insensitive to the choice of cutoff distances.

After the effective areas of truss members are determined, the elastic modulus of concrete $\left(E_{c}\right)$ is assigned to each truss member. Member forces for the statically indeterminate strut-and-tie model are obtained from the analysis. Given the force, the crosssectional area for the tension member is then calculated by

$$
A_{s}=\frac{T}{f_{y}}
$$

where $A_{s}=$ required area for a tension tie. The $T$ and $f_{y}$ represent the tensile force and yield stress of the reinforcement. Care must be taken as the real distribution of bars may need to be considered when treating the nodes and checking for adequate anchorage. Finally, consideration of secondary reinforcements may be needed to control cracking.

\section{Evaluation of Concrete Compressive Strength}

To evaluate the effective compressive strength of the struts and nodes, an analytical three-dimensional failure criterion for con-

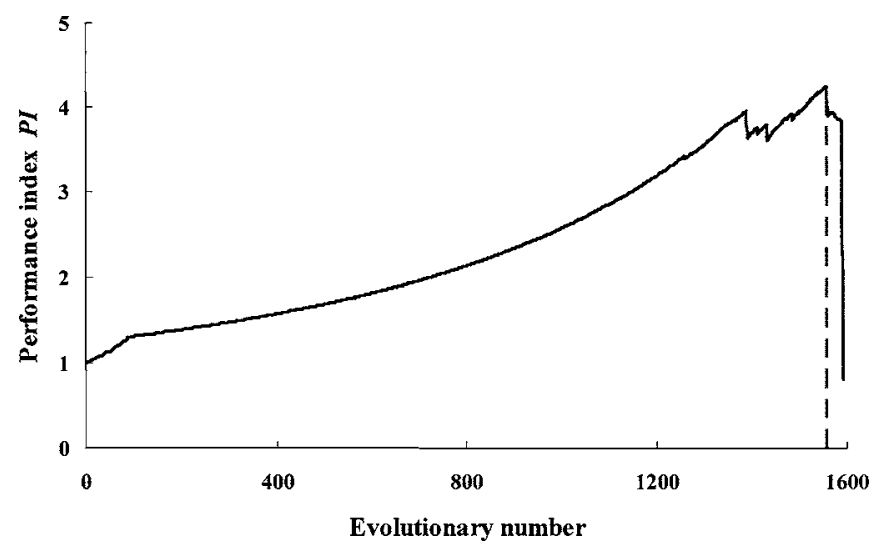

Fig. 7. Performance index history of anchorage block 


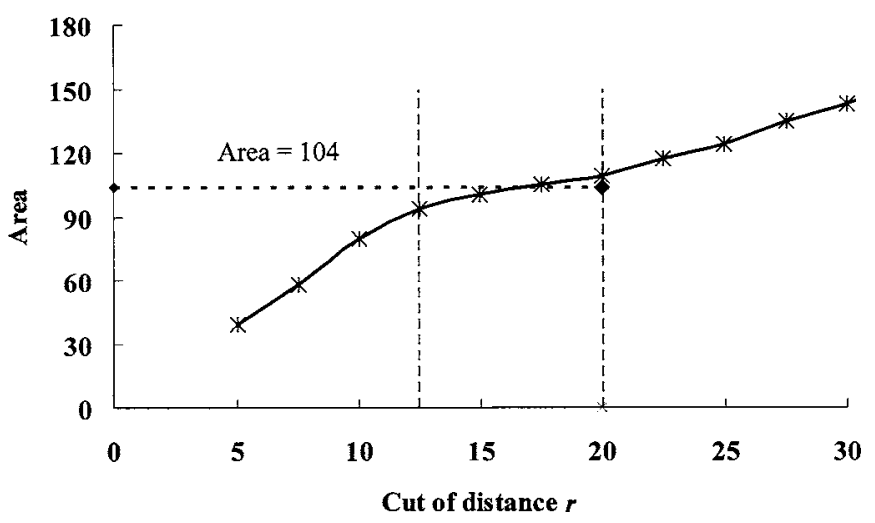

Fig. 8. Effective area versus cutoff distance $r$ for truss member $C_{A 3}$ (unit: $\mathrm{cm}$ )

crete is utilized. The strength of concrete under multiaxial stresses is a function of the stress state and can only be properly determined by considering the interaction of various stress components. The failure evaluation is only carried out for the initial continuum structure, not during the evolutionary process. This is because the evolutionary process is used to help engineers establish the corresponding strut-and-tie model. In real world, no elements are removed from the considered structure.

For two-dimensional cases, Yun (2000) employed the biaxial stress failure envelope proposed by Kupfer and Gerstle (1973) to evaluate the compressive strength of nodal zones from finite element analyses. In this study, Ottosen's four-parameter strength criterion for concrete (Ottosen 1977) is adopted. Ottosen's strength criterion is in good agreement with the experimental results over a wide range of stress states (Chen 1982). The fourparameter failure function can be described as

$$
\begin{gathered}
f\left(I_{1}, J_{2}, \cos 3 \theta\right)=a \frac{J_{2}}{\left(f_{c}^{\prime}\right)^{2}}+\lambda(\cos 3 \theta) \frac{\sqrt{J_{2}}}{f_{c}^{\prime}}+b \frac{I_{1}}{f_{c}^{\prime}}-1 \\
\cos 3 \theta=\frac{3 \sqrt{3}}{2} \frac{J_{3}}{J_{2}^{3 / 2}}
\end{gathered}
$$

where $a$ and $b=$ material parameters; $I_{1}=$ first invariant of the stress tensor and $J_{2}$ and $J_{3}=$ second and third invariants of the deviatoric stress tensor; $f_{c}^{\prime}=$ uniaxial compressive strength of concrete; and

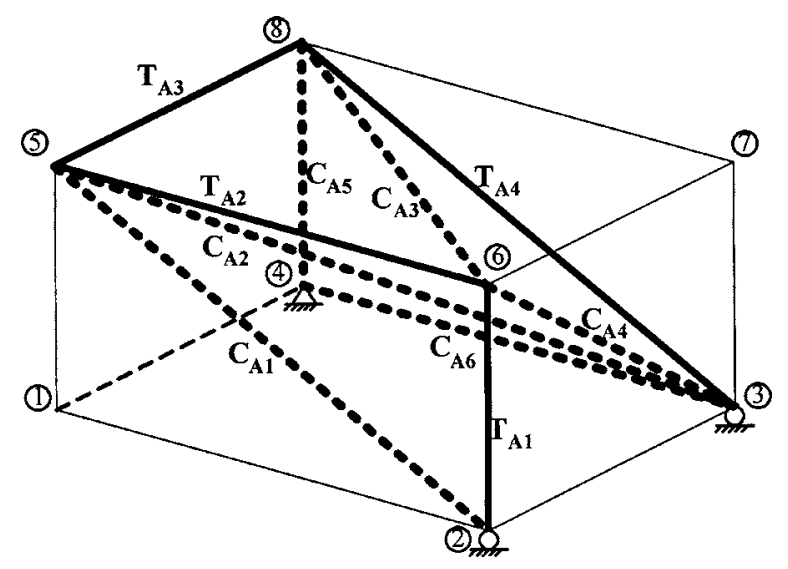

Fig. 9. Strut-and-tie model of anchorage block resulting from RESO method
Table 3. Member Forces in Anchorage Block Design Example by RESO Method

\begin{tabular}{lccccc}
\hline Members & $\begin{array}{c}\text { Length } \\
(\mathrm{cm})\end{array}$ & $\begin{array}{c}\text { Member } \\
\text { force } \\
(\mathrm{kN})\end{array}$ & Members & $\begin{array}{c}\text { Length } \\
(\mathrm{cm})\end{array}$ & $\begin{array}{c}\text { Member } \\
\text { force } \\
(\mathrm{kN})\end{array}$ \\
\hline $\mathrm{T}_{\mathrm{A} 1}$ & 40.0 & 580.7 & $\mathrm{C}_{\mathrm{A} 1}$ & 78.5 & $-1,139.1$ \\
$\mathrm{~T}_{\mathrm{A} 2}$ & 67.5 & $3,171.2$ & $\mathrm{C}_{\mathrm{A} 2}$ & 98.8 & $-2,665.1$ \\
$\mathrm{~T}_{\mathrm{A} 3}$ & 60.0 & 1,618 & $\mathrm{C}_{\mathrm{A} 3}$ & 90.3 & $-3,761.2$ \\
$\mathrm{~T}_{\mathrm{A} 4}$ & 78.5 & $3,267.8$ & $\mathrm{C}_{\mathrm{A} 4}$ & 72.1 & $-1,047.0$ \\
- & - & - & $\mathrm{C}_{\mathrm{A} 5}$ & 40.0 & -5.9 \\
- & - & - & $\mathrm{C}_{\mathrm{A} 6}$ & 67.5 & -9.52 \\
\hline
\end{tabular}

$\lambda=$ function of $\cos 3 \theta$ and can be determined from the following

$$
\begin{gathered}
\lambda=k_{1} \cos \left[\frac{1}{3} \cos ^{-1}\left(k_{2} \cos 3 \theta\right)\right] \text { for } \cos 3 \theta \geqslant 0 \\
\lambda=k_{1} \cos \left[\frac{\pi}{3}-\frac{1}{3} \cos ^{-1}\left(-k_{2} \cos 3 \theta\right)\right] \text { for } \cos 3 \theta \leqslant 0
\end{gathered}
$$

where $k_{1}$ and $k_{2}=$ material parameters. The values of $a, b, k_{1}$, and $k_{2}$ depend on the ratio of the uniaxial tensile strength $f_{t}$ to the uniaxial compressive strength $f_{c}^{\prime}$ (Table 1). For a given stress state, if the value of the failure function, $f\left(I_{1}, J_{2}, \cos 3 \theta\right)$, is greater than zero, it means that concrete will fail under this state.

We note that only those elements under the compressive stress state need to be checked by Ottosen's four-parameter strength criterion. A stress state that satisfies

$$
I_{1} \leqslant 0
$$

is considered compressive. The tensile elements $\left(I_{1}>0\right)$, anticipated to fail in the cracking type, represent tension members of a strut-and-tie model. Reinforcing steel and prestressing tendons will be arranged for these tension members.

In addition to evaluating the compressive strength of concrete, the strength criterion can be used to determine load-carrying capacity of the structure. To this end, a stress ratio $\beta$ is defined as (Fig. 3)

$$
\beta=\frac{\sqrt{J_{2}}}{\sqrt{J_{2 f}}}
$$

where $J_{2}$ denotes the second deviatoric stress invariant of a stress state due to a given load. The $J_{2 f}$ denotes the failure deviatoric stress invariant by solving the quadratic equation defined by letting Eq. (10) be zero. For all the compressive elements satisfying Eq. (13) in an initial continuum, we can calculate the stress ratio $\beta$ according to Eq. (14) and consequently find the maximum value $\beta_{\max }$. The load carrying capacity can then be determined by dividing the given load by $\beta_{\max }$. It is worth noting that the aboveobtained load-carrying capacity is in general rather conservative because it assumes that the first occurrence of the limit state of an element represents the limit state of a whole structure.

\section{Flowchart for Proposed Design Methodology}

Putting it all together, a flowchart for the proposed design methodology is shown in Fig. 4. We first model the structure with solid finite elements and evaluate the stress ratio $\beta$ for each compressive element. An optimal topology is then generated using the RESO method. Through the optimal topology, a truss model is 


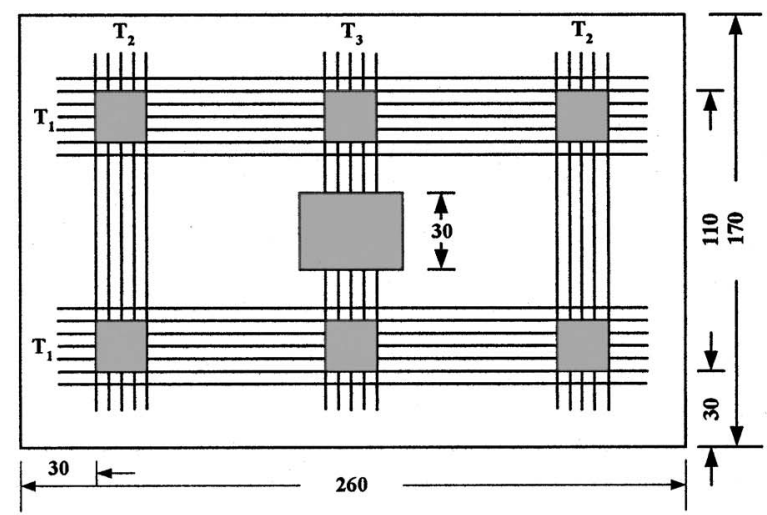

(a)

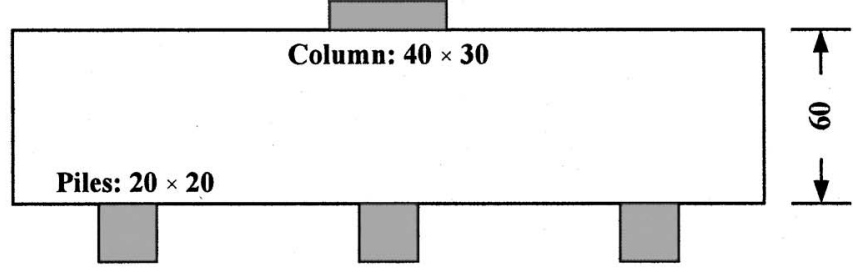

(b)

Fig. 10. Pile cap design example (unit: $\mathrm{cm}$ ): (a) top view; (b) side view

developed interactively. The effective areas of the truss members can be computed by the proposed stiffness finding method. Consequently, the member forces of the truss model can be obtained. Finally from the forces of the tension members, the required reinforcements can then be determined. Unlike the conventional methodology illustrated in Fig. 1, most tasks in the proposed methodology are performed automatically or semiautomatically.

\section{Numerical Examples}

The feasibility of the proposed strut-and-tie design methodology for three-dimensional reinforced structures is demonstrated below. In these examples, the eight-node brick element is used for the finite element analysis (Cook et al. 2002). These examples are conducted using an in-house object-oriented program, developed to maximize flexibility and maintainability for future extension. Additionally, interactive computer graphics are utilized to aid modeling processes in three dimensions. Detailed features of the program can be found in Huang (2003).

\section{Anchorage Block}

An anchorage block is considered in this example. The block is supported by two rollers and one hinge at the corners of the lower surface. The configuration and external loads of the anchorage block are shown in Fig. 5(a). The corresponding strut-and-tie model suggested by FIB (2002) is shown in Fig. 5(b). In the figure, the solid and dashed lines represent tension ties and compressive struts, respectively. The member forces of the FIB model are listed in Table 2.

The design domain is discretized with 2,250 equal-sized finite elements. Each side of the element is equal to $4.5 \mathrm{~cm}$. The elastic modulus $E_{c}$ and Poisson's ratio $v$ of concrete are assumed to be 26,000 MPa and 0.2, respectively. Fig. 6(a) shows the optimal topology developed by the RESO method with the highest value of the performance index. Fig. 6(b) shows the truss model derived from the evolved topology. The performance index history is shown in Fig. 7; it takes 1,556 evolution steps to reach the optimal topology.

From the truss model in the evolved topology [Fig. 6(b)], designers can select an appropriate cutoff distance $r$ to calculate the effective areas and consequently member forces of the truss. Fig. 8 shows the relationship between cutoff distances $r$ and computed areas for the member $\mathrm{C}_{\mathrm{A} 3}$ in Fig. 9. From Fig. 8, we can observe a tendency that in a specific range of cutoff distances, the increasing rate of effective areas is reduced. In this range, the computed member forces are relatively insensitive to the choice of cutoff distances. The member forces computed in this example are listed in Table 3.

The strut-and-tie model suggested by the RESO method is shown in Fig. 9. From Figs. 5(b) and 9, one can observe that the strut-and-tie model developed by the RESO method is similar to that of FIB (2002). The main difference occurs in the transmission of the upward load $P_{Z 8}$. In Fig. 5(b) (FIB 2002), the load $P_{Z 8}$ is carried through the tension member $\mathrm{T}_{7}$. In the RESO method or Fig. 9, however, the load $P_{Z 8}$ is carried by both the tension member $\mathrm{T}_{\mathrm{A} 4}$ and the compressive member $\mathrm{C}_{\mathrm{A}_{5}}$, which makes the tension member $\mathrm{T}_{6}$ of Fig. 5(b) become compressive member $\mathrm{C}_{\mathrm{A} 6}$ of Fig. 9.

There are two possible reasons to explain the difference between the two. First, the model suggested by the RESO method depends mainly on the material efficiency in carrying external loading. In general, the summing product of the tie length and the tensile force can be used as a simple criterion for optimizing a strut-and-tie model (Schlaich et al. 1987). In this example, the proposed model has a smaller value than that of the FIB design example; it is thus believed to be an optimum one. Second, the model suggested in the FIB design examples may need to take the construction process into account. Thus the FIB model leads to the reinforcement arrangements being parallel to the edges of the structure in order to simplify construction process.

Table 4. Summary of Reinforcements in Pile Cap Design Example

\begin{tabular}{llc}
\hline Members & $\begin{array}{c}\text { Steel } \\
\text { reinforcement }\end{array}$ & $\begin{array}{c}\text { Area of steel } \\
\left(\mathrm{mm}^{2}\right)\end{array}$ \\
\hline \multirow{3}{*}{$\mathrm{T}_{1}$} & 7-No. $10^{\text {a }}$ at $45 \mathrm{~mm}$ & 700 (layer 1) \\
& 7-No. 10 at $45 \mathrm{~mm}$ & 700 (layer 2) \\
& 7-No. 10 at $45 \mathrm{~mm}$ & 700 (layer 3) \\
$\mathrm{T}_{2}$ & 3-No. 10 at $45 \mathrm{~mm}$ & 300 (layer 1) \\
& 5-No. 10 at $45 \mathrm{~mm}$ & 500 (layer 2) \\
& 3-No. 10 at $45 \mathrm{~mm}$ & 300 (layer 3) \\
$\mathrm{T}_{3}$ & 4-No. 10 at $70 \mathrm{~mm}$ & 400 (layer 1) \\
& 4-No. 10 at $70 \mathrm{~mm}$ & 400 (layer 2) \\
\hline
\end{tabular}

${ }^{\mathrm{a}}$ No. 10 is a $11.3 \mathrm{~mm}$ diam bar with a cross-sectional area of $100 \mathrm{~mm}^{2}$ 


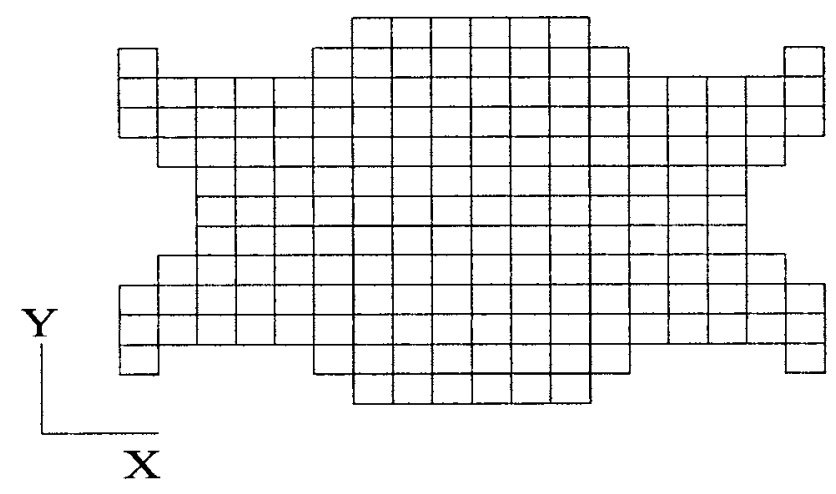

(a)

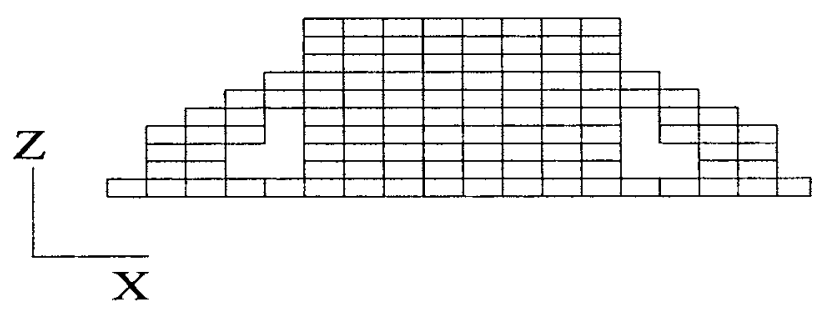

(b)

Fig. 11. Pile cap design example by RESO method: (a) topology from RESO (top view); (b) topology from RESO (side view)

\section{Pile Cap}

The example is one of the six pile caps conducted experimentally by Adebar et al. (1990) to examine the suitability of threedimensional strut-and-tie models for the pile cap design. Details of the test specimen are given in Fig. 10 and Table 4. The pile cap is supported on six piles and designed using a strut-and-tie model for an applied load of 3,000 kN acting on the column. The elastic modulus $E_{c}$ and Poisson's ratio $v$ for concrete are assumed to be 26,000 MPa and 0.2, respectively. The concrete cylinder uniaxial compressive and tensile strength are 27.1 and $3.7 \mathrm{MPa}$, respectively. Consequently, the ratio of concrete tensile strength to compressive strength is roughly taken as 0.12 in the four-parameter failure criterion. In addition, the yield stress and nominal area for Number 10 steel are $479 \mathrm{MPa}$ and $100 \mathrm{~mm}^{2}$, respectively.

The design domain from Fig. 10 is discretized with 4,420 equal-sized finite elements. The length, width, and height for an element are 10,10, and $6 \mathrm{~cm}$, respectively. The final evolutionary topology is reached when the elements in conjunction with the four outer piles are ready to be removed. The resulting topology is shown in Fig. 11. One can observe that the two legs connected to the middle piles comprise more elements than the other piles. This load-carrying mechanism agrees well with the experimental observations in which these two piles resist the majority of loads (Adebar et al. 1990).

From the final topology, designers can develop a strut-and-tie model as shown in Fig. 12, where the solid and dashed lines represent tension ties and compression struts, respectively. This model is the same as that of Adebar et al. (1990) which was obtained from the designers' experiences. For this example, a cut-

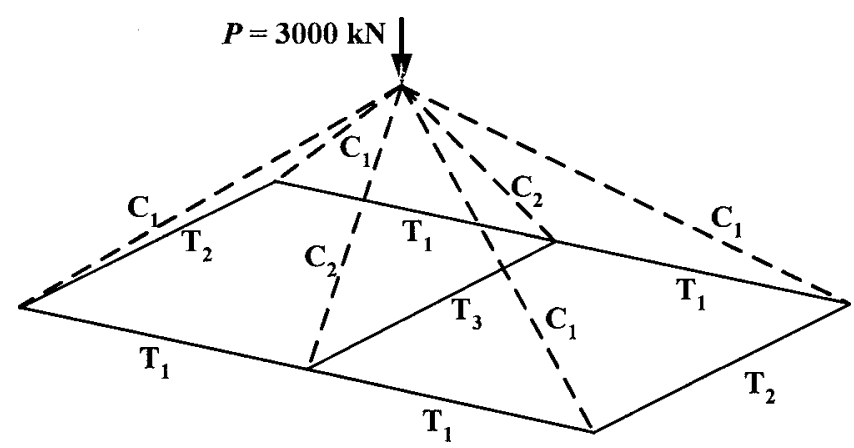

Fig. 12. Strut-and-tie model suggested by RESO method for pile cap design example off distance of $40 \mathrm{~cm}$ is employed. The calculated effective areas and member forces are listed in Table 5. As one would expect, the $\mathrm{C}_{2}$ members in the middle have larger cross-sectional areas than the other members. The required reinforcement areas of the strutand-tie model are shown in Table 6.

It is worth noting that designers have to take specifications about temperature reinforcements (ACI 2002) into consideration. The minimum ratio for temperature reinforcements to the gross concrete area is 0.0018. Consequently, the final reinforcement arrangements for the strut-and-tie model are listed in Table 6. One can observe that the longitudinal reinforcements $\left(\mathrm{T}_{1}\right)$ and the outer transverse reinforcements $\left(\mathrm{T}_{2}\right)$ are increased to satisfy the specification.

It is interesting to compare the reinforcement requirements computed from the optimal topology with those obtained empirically in Adebar et al. (1990). From Table 6, one can observe that the derived strut-and-tie model by the RESO method uses a total of $2,800 \mathrm{~mm}^{2}$ reinforcements (or $3,600 \mathrm{~mm}^{2}$ with the temperature specification taken into account). On the other hand, the empirical arrangement in Adebar et al. (1990) from Table 4 uses a total of $4,400 \mathrm{~mm}^{2}$ reinforcements. This is expected because the optimal topology from the RESO method should produce a more efficient load-carrying mechanism.

Finally, the ultimate load of the pile cap from the experimental measurement is $2,892 \mathrm{kN}$ (Adebar et al.). The external load used in the finite element model is $2,980 \mathrm{kN}$, and the maximum stress ratio $\beta_{\max }$ is 1.053 . In other words, the ultimate load for concrete failure predicted by this study is $2,830 \mathrm{kN}$. The predicted ultimate load is less than the experimental result by only $2.1 \%$.

\section{Conclusions}

In this paper, a design methodology for developing a threedimensional strut-and-tie model is presented. A strut-and-tie

Table 5. Areas and Member Forces in Pile Cap Design Example from RESO Method

\begin{tabular}{lcr}
\hline Members & $\begin{array}{c}\text { Cross section area } \\
\left(\mathrm{cm}^{2}\right)\end{array}$ & $\begin{array}{c}\text { Member force } \\
(\mathrm{kN})\end{array}$ \\
\hline $\mathrm{T}_{1}$ & 1,618 & 166.54 \\
$\mathrm{~T}_{2}$ & 442.5 & 83.27 \\
$\mathrm{~T}_{3}$ & 4,200 & $1,183.46$ \\
$\mathrm{C}_{1}$ & 2,423 & -207.92 \\
$\mathrm{C}_{2}$ & 4,634 & $-1,769.09$ \\
\hline
\end{tabular}


Table 6. Summary of Reinforcements in Pile Cap Design Example from RESO Method

\begin{tabular}{|c|c|c|c|c|}
\hline \multirow[b]{2}{*}{ Members } & \multicolumn{2}{|c|}{ From strut-and-tie model } & \multicolumn{2}{|c|}{ Temperature steel included } \\
\hline & Reinforcement & $\begin{array}{l}\text { Area } \\
\left(\mathrm{mm}^{2}\right)\end{array}$ & Reinforcement & $\begin{array}{c}\text { Area } \\
\left(\mathrm{mm}^{2}\right)\end{array}$ \\
\hline & & & 5-No. 10 at $45 \mathrm{~mm}$ & 500 (layer 1) \\
\hline $\mathrm{T}_{1}$ & $3-N o .10$ at $70 \mathrm{~mm}$ & 300 & 5-No. 10 at $45 \mathrm{~mm}$ & 500 (layer 2) \\
\hline \multirow[t]{2}{*}{$\mathrm{T}_{2}$} & 2-No.10 at $45 \mathrm{~mm}$ & 200 & 3-No. 10 at $45 \mathrm{~mm}$ & 300 \\
\hline & 7-No.10 at $45 \mathrm{~mm}$ & 700 (layer 1) & 7-No. 10 at $45 \mathrm{~mm}$ & 700 (layer 1) \\
\hline \multirow[t]{2}{*}{$\mathrm{T}_{3}$} & 9-No.10 at $45 \mathrm{~mm}$ & 900 (layer 2) & 9-No. 10 at $45 \mathrm{~mm}$ & 900 (layer 2) \\
\hline & 7-No.10 at $45 \mathrm{~mm}$ & 700 (layer 3) & 7-No. 10 at $45 \mathrm{~mm}$ & 700 (layer 3) \\
\hline
\end{tabular}

model for the considered reinforced concrete structure is established based on the RESO method. For a statically indeterminate case, a simple stiffness finding algorithm is developed to estimate the relative stiffness of the truss members from the evolved topology. The concrete compressive strength evaluation is performed by Ottosen's four-parameter strength criterion.

Two design examples demonstrate the suitability of the proposed methodology. In the anchorage block example, the derived strut-and-tie model by the RESO method agrees with those from design experience. A small difference between the two can mainly contribute to the issue concerning with construction in practice. In the pile cap example, we observe that the load-carrying mechanism from the evolved topology agree well with the experimental measurements. The load-carrying capacity of the structure is also well predicted by Ottosen's failure criterion.

Finally, we must emphasize that the proposed method is mainly based on linear elastic analysis. The effects of concrete crack are indirectly taken into account while evaluating concrete compressive strength. However, the effects of the tension stiffening, the arrangement of steel reinforcements and the degree of disruption of the nodal zone due to the incompatibility of tensile strains in the ties are not considered. Furthermore, the effects of nonlinear load-deformation responses and softening of concrete are not taken into account. These limitations and uncertainties need to be addressed in the future.

\section{Notation}

The following symbols are used in this paper:

$A_{i}=$ relative area of $i$ th truss member in strut-and-tie models;

$A_{s}=$ cross-sectional area of reinforcement;

$d_{p q}=$ distance of $p$ th remaining element to projected point on $i$ th truss member;

$\mathrm{ER}=$ evolution rate;

$f_{c}^{\prime}=$ uniaxial compressive strength of concrete;

$f_{y}=$ yield stress of reinforcement;

$I_{1}=$ first invariant of stress tensor;

$J_{2}=$ second invariant of deviatoric stress tensor;

$J_{3}=$ third invariant of deviatoric stress tensor;

$\left[k_{i}\right]=$ element stiffness matrix corresponding to $i$ th elements;

$L_{i}=$ length of $i$ th truss element;

$\mathrm{PI}=$ performance index;

$\mathrm{RR}=$ rejection ratio;

$T=$ tension force in strut-and-tie models;

$\left\{u_{i}\right\}=$ displacement vector corresponding to $i$ th element;

$V=$ volume of structure;

\author{
$V_{i}=$ volume of $i$ th truss element; \\ $W=$ strain energy of structure; \\ $w_{i}=$ strain energy density of $i$ th element; \\ $w_{\text {ave }}=$ average strain energy density of structure; \\ $(x, y, z)=$ coordinates; and \\ $\beta=$ stress ratio of compression elements.
}

\section{Acknowledgment}

This research was supported by the National Science Council of the Republic of China through Grant No. NSC 91-2211-E-002078.

\section{References}

Adebar, P., Kuchma, D., and Collins, M. P. (1990). "Strut-and-tie models for the design of pile caps: An experimental study." ACI Struct. J., 87(1), 81-92.

Ali, M. A. (1997). "Automatic generation of truss models for the optimal design of reinforced concrete structures." Ph.D. thesis, Cornell Univ., Ithaca, N.Y.

Ali, M. A., and White, R. N. (2001). "Automatic generation of truss model for optimal design of reinforced concrete structures." $A C I$ Struct. J., 98(4), 431-442.

American Concrete Institute (ACI) Committee 318. (2002). "Building code requirements for structural concrete." ACI 318-02, Farmington Hills, Mich.

American Society for Civil Engineers - American Concrete Institute (ASCE-ACI) Committee 445. (1998). "Recent approaches to shear design of structural concrete." J. Struct. Eng., 124(12), 1375-1417.

Biondini, F., Bontempi, F., and Malerba, P. G. (2001). "Stress path adapting strut-and-tie models in cracked and uncracked R.C. elements." Struct. Eng. Mech., 12(6), 685-698.

Chen, W. F. (1982). Plasticity in reinforced concrete, McGraw-Hill Inc., Singapore.

Cook, R. D., Malkus, D. S., Plesha, M. E., and Witt, R. J. (2002). Concepts and applications of finite element analysis, 4th Ed., Wiley, New York.

Fédération Internationle de la Précontrainte (FIP). (1996). Recommendation-Practical design of structural concrete, London.

Fédération Internationale Du Béton (FIB). (2002). "Design examples for the 1996 FIP recommendations-Practical design of structural concrete." Technical Rep., International Federation for Structural Concrete (fib), London.

Hinton, E., and Sienz, J. (1995). "Fully stressed topological design of structures using an evolutionary procedure." Eng. Comput., 12(2), 229-244.

Hsu, T. T. C. (1993). Unified theory of reinforced concrete, CRC Press, Boca Raton, Fla. 
Huang, C. W. (2003). "Theory and software development of strut-and-tie models by using topology optimization techniques." Ph.D. thesis, National Taiwan Univ., Taipei, Taiwan (in Chinese).

Kupfer, H., and Gerstle, K. H. (1973). "Behavior of concrete under biaxial stresses.” J. Eng. Mech. Div., Am. Soc. Civ. Eng., 99(4), 853-866.

Li, Q., Steven, G. P., and Xie, Y. M. (2001). "A simple checkerboard suppression algorithm for evolutionary structural optimization." Struct. Multidiscip. Optim., 22(3), 230-239.

Liang, Q. Q., and Steven, G. P. (2002). “A performance-based optimization method for topology design of continuum structures with mean compliance constraints." Comput. Methods Appl. Mech. Eng., 191(13-14), 1471-1489.

Liang, Q. Q., Uy, B., and Steven, G. P. (2002). "Performance-based optimization for strut-tie modeling of structural concrete." J. Struct. Eng., 128(6), 815-823.

Liang, Q. Q., Xie, Y. M., and Steven, G. P. (2000). “Topology optimization of strut-and-tie models in reinforced concrete structures using an evolutionary procedure." ACI Struct. J., 97(2), 322-330.
MacGregor, J. G. (1997). Reinforced concrete mechanics and design, 3rd Ed., Prentice-Hall, Upper Saddle River, N.J.

Ottosen, N. S. (1977). "A failure criterion for concrete." J. Eng. Mech. Div., Am. Soc. Civ. Eng., 103(4), 527-535.

Schlaich, J., and Schäfer, K. (1991). "Design and detailing of structural concrete using strut-and-tie models." Struct. Eng., 69(6), 113-125.

Schlaich, J., Schäfer, K., and Jennewein, M. (1987). "Toward a consistent design of structural concrete.” PCI J., 32(3), 75-150.

Tjhin, T. N., and Kuchma, D. A. (2002). "Computer-based tools for design by strut-and-tie method: Advances and challenges." ACI Struct. J., 99(5), 586-594.

Xie, Y. M., and Steven, G. P. (1993). "A simple evolutionary procedure for structural optimization.” Comput. Struct., 49(5), 885-896.

Yun, Y. M. (2000). "Computer graphics for nonlinear strut-tie model approach." J. Comput. Civ. Eng., 14(2), 127-133.

Zhao, C., Hornby, P., Steven, G. P., and Xie, Y. M. (1998). "A generalized evolutionary method for numerical topology optimization of structures under static loading conditions." Struct. Optim., 15(3/4), 251-260. 